\title{
Effect of Geometrical Parameters on Deflection of Different Chassis Component Sections
}

\author{
Sumedh Kousadikar , Mangesh Yadav, Dattaprasad Lomate and Manoj Ukhande
}

Kalyani Centre for Technology \& Innovation, Bharat Forge Ltd. Pune, India.

\begin{abstract}
Many of the chassis and suspension components are made from variety of sections. Most of them are the robust components assembled critically with other chassis part of the vehicle. The chassis components are used to carry the weight of the vehicle as well as some of them facilitates steering and absorb shocks due to road surface variations. Present competitive market of automotive industry demands for low cost and light weight components. Therefore more emphasis is towards design optimization for reducing weight while maintaining the structural stiffness unchanged. This paper more focuses on effect of geometrical parameters of different sections of chassis components on deflection characteristics by using a hybrid approach of statistical Taguchi method based on orthogonal array and Finite elements analysis (FEA). Using this method the most influencing parameters for deflection are identified through sensitivity analysis. The results obtained are used as a design guideline for generating optimized components with improved deflection performance.
\end{abstract}

\section{Introduction}

The present competitive market of automotive industry demands for low cost and light weight components. As emission norms are becoming more and more stringent, the subsequent challenges in reducing the greenhouse gas emissions are forcing the vehicle manufactures to develop light weight vehicles without compromising its strength and stiffness criteria. Recent research in the US shows that on average across all vehicle models every $100 \mathrm{~kg}$ weight reduction will achieve a reduction in fuel consumption of $0.39 \mathrm{~L} / 100 \mathrm{~km}$ for cars and $0.48 \mathrm{~L} / 100 \mathrm{~km}$ for light trucks [1]. So many of the OEM's are concentrating on the redesigning the chassis/suspension system to smaller and lighter extent for getting substantial reduction in the total vehicle weight.

In chassis applications the opportunities to reduce weight have two major benefits. Any contribution to fuel economy reduction is important, but for many chassis and suspension parts, the reduction of unsprung weight is even more significant, offering improvement in handling performance and drive dynamics. Many of the chassis and suspension components e.g. axle beams, body frames are made from variety of sections. The automotive axle beam is one of the robust components assembled critically with other chassis part of the vehicle. The strength and stiffness of these components is an important aspect to avoid sudden failure. To solve these problems, most of the researchers have been focused on improving material strength, replacement of alloy grades and geometry weight optimization, etc. These techniques will definitely reduce the weight of the component but adversely affects the deflection characteristics. However to balance the weight and stresses within controlled deflection for such critically loaded components, the authors believe that, combination of statistical approach and Finite elements analysis (FEA) are an efficient way to optimize the critically loaded components. As most of the chassis components are in simply supported and cantilever loading conditions, instead of taking entire component; the study on different geometrical sections is an effective and quick way of optimization.

The objective of this study is to design stiffer sections with improved moment of inertia (I) which resulted into reduced weight and deflection at cantilever loading condition. The deflection of simple beam at cantilever loading condition is as given (1)

$$
\text { Deflection }=P L 3 / 3 E I
$$

where $\mathrm{P}$ is applied load, 1 is length of the beam, E is the young's modulus and I is the moment of inertia.

This paper studied the geometrical parameter effect of one chassis component e.g. axle beam which consist of different section mostly I and T shapes. The optimization is carried out using Taguchi orthogonal array and Finite element analysis. These optimized sections generated guidelines for designing the component with improved deflection performance [2].

\section{Experimental works}

A multi-disciplinary approach of Taguchi analysis in conjunction with FEA was used for the optimization. A 
Taguchi orthogonal array method is used as a statistical approach for optimization. The Taguchi method involves reducing the variation in a process through robust design of experiments. Taguchi method is used to investigate how different parameters affect the mean and variance of a process performance characteristic that defines how well the process is functioning. The experimental design proposed by Taguchi involves orthogonal arrays to organize the parameters affecting the process and the levels at which they will be varies.

\section{1. Statistical methodology}

There are many geometrical parameters to affect the deflection of the considered beam geometry. In this study, we have chosen three sections as control factors A. Start section, B. Middle section and C. End section as shown in Fig. 1. The levels of the factors are listed in Table I.

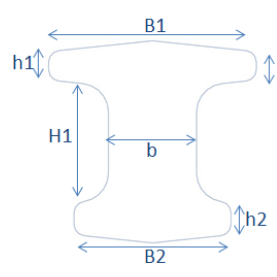

(A)

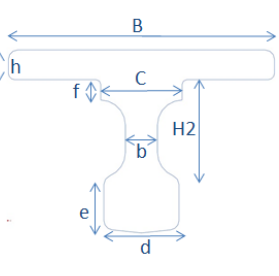

(B)

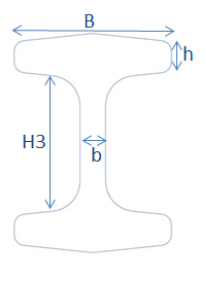

(C)
Figure 1. Sections considered for optimisation

Table 1 Levels of the control factors.

\begin{tabular}{|c|c|c|c|}
\hline Label & Factor Name & Level1 & Level 2 \\
\hline A & Start Section & Thicker & Slimmer \\
\hline B & Middle section & Thicker & Slimmer \\
\hline C & End section & Thicker & Slimmer \\
\hline
\end{tabular}

Each section consists of four to five geometrical parameters. The parameters notations are described in Table II.

Table 2 Parameter notations for sections

\begin{tabular}{|c|c|}
\hline \multicolumn{2}{|c|}{ Start Section A } \\
\hline h1 & Upper flange thickness \\
\hline B1 & Upper flange width \\
\hline $\mathrm{h} 2$ & Lower flange thickness \\
\hline $\mathrm{B} 2$ & Lower flange width \\
\hline $\mathrm{b}$ & Web Thickness \\
\hline H1 & Web height \\
\hline \multicolumn{2}{|c|}{ Middle section B } \\
\hline $\mathrm{h}$ & Upper flange thickness \\
\hline B & Upper flange width \\
\hline $\mathrm{C}$ & Resting support width \\
\hline $\mathrm{f}$ & Resting support height \\
\hline $\mathrm{b}$ & Web Thickness \\
\hline $\mathrm{H} 2$ & Pad height \\
\hline $\mathrm{e}$ & Lower flange height \\
\hline \multicolumn{2}{|c|}{ End section $\mathrm{C}$} \\
\hline h1 & Flange thickness \\
\hline B & Flange width \\
\hline $\mathrm{b}$ & Web Thickness \\
\hline H3 & Flange height \\
\hline
\end{tabular}

The experiments are designed based on Taguchi $2 \mathrm{X} 2$ orthogonal array with 16 numbers of experiments for each section. The parameters are varied within two levels as targeted. The Table 3 shows Taguchi $2 \times 2$ orthogonal array with combination of levels of factors. [3] These factors $1,2,3$, etc are replaced with original geometrical parameter dimensions considering levels and targets.

Table 3 Taguchi $2 \mathrm{X} 2$ orthogonal array

\begin{tabular}{|l|c|c|c|c|c|c|}
\hline & Parameter1 & Parameter2 & Parameter3 & Parameter4 & Parameter5 & Parameter6 \\
\hline EXP 1 & 1 & 1 & 1 & 1 & 1 & 1 \\
\hline EXP 2 & 1 & 1 & 1 & 2 & 1 & 2 \\
\hline EXP 3 & 1 & 1 & 2 & 1 & 2 & 1 \\
\hline EXP 4 & 1 & 1 & 2 & 2 & 2 & 2 \\
\hline EXP 5 & 1 & 2 & 1 & 1 & 2 & 2 \\
\hline EXP 6 & 1 & 2 & 1 & 2 & 2 & 1 \\
\hline EXP 7 & 1 & 2 & 2 & 1 & 1 & 2 \\
\hline EXP 8 & 1 & 2 & 2 & 2 & 1 & 1 \\
\hline EXP 9 & 2 & 1 & 1 & 1 & 2 & 2 \\
\hline EXP 10 & 2 & 1 & 1 & 2 & 2 & 1 \\
\hline EXP 11 & 2 & 1 & 2 & 1 & 1 & 2 \\
\hline EXP 12 & 2 & 1 & 2 & 2 & 1 & 1 \\
\hline EXP 13 & 2 & 2 & 1 & 1 & 1 & 1 \\
\hline EXP 14 & 2 & 2 & 1 & 2 & 1 & 2 \\
\hline EXP 15 & 2 & 2 & 2 & 1 & 2 & 1 \\
\hline EXP 16 & 2 & 2 & 2 & 2 & 2 & 2 \\
\hline
\end{tabular}

Based on the decided 16 number of experiments, 16 geometries of section have been modeled using 3D CAD packages and FE analysis has been carried out with the help analysis tools. Based on these experiments, a set of optimized parameters has been identified. These parameters are referred as Taguchi optimized parameters. The evaluated set further analyzed for sensitivity analysis and most influencing parameter on deflection is evaluated.

\subsection{FE analysis}

The FE analysis is carried out at cantilever loading condition. The commercial software packages ANSYS workbench and UG NX is used for analysis and 3D CAD modeling. The section geometry is kept as similar length of $200 \mathrm{~mm}$ for all analysis. The sections are finely meshed with the mesh size of $1 \mathrm{~mm}$ before analysis. One end of the section is fixed with frictionless support and at other end vertical load of $41.4 \mathrm{KN}$ is applied. The analysis flow is as shown in Fig. 2. The applied load in this example is considered based on maximum load acting on the respective beam section after assembly and loading condition. The analysis methodology for all the experiments is kept similar. Based on the analysis, the results of deflection, equivalent stresses and weight is calculated. Series of analysis is conducted for other two sections to obtain the optimum weight for allowable.

\subsection{Sensitivity analysis}

The sensitivity analysis is carried out using $\mathrm{S} / \mathrm{N}$ (Signal to noise) ratio which is useful to check the robustness of the control factors. Noises are unwanted or uncontrollable factors given from the surroundings of the system. The response functions are weight, equivalent stresses and deflection. There are three categories of quality characteristic in the analysis of the $\mathrm{S} / \mathrm{N}$ ratio, (i) thelower-the-better, (ii) the-higher-the-better and (iii) the- 
nominal-the better. Regardless of the category of the quality characteristic, process parameter settings with the highest $\mathrm{S} / \mathrm{N}$ ratio always yield the optimum quality with minimum variance. The category the-lower-the-better was used to calculate the $\mathrm{S} / \mathrm{N}$ ratio for deflection [4].

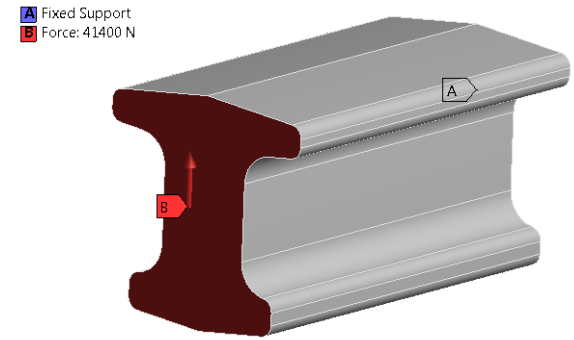

(A)

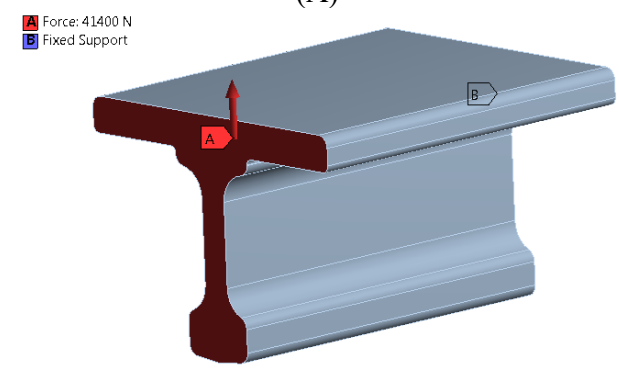

(B)

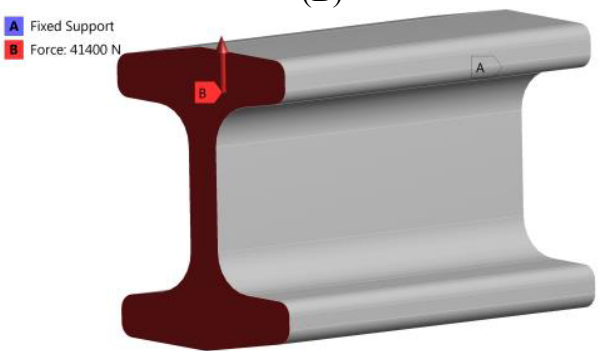

(C)

Figure 2. FE analysis of the sections

\subsection{Results and discussions}

The equivalent stresses and deflection are measured for each set of parameter using FEA in Ansys. The results are as shown in Fig. 3, and the results of FEA are analyzed for sensitivity using Minitab [5].

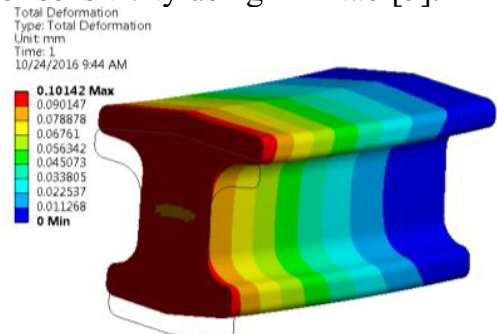

(A)

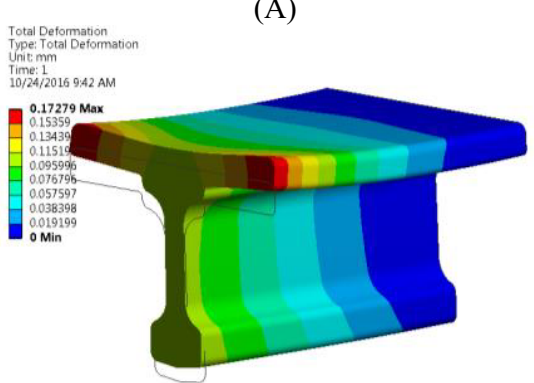

(B)

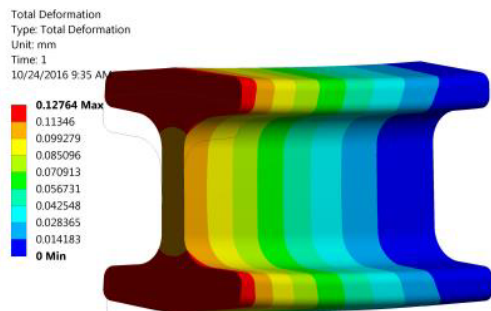

(C)

Figure 3. FE analysis results of the sections under cantilever loading condition.

The $\mathrm{S} / \mathrm{N}$ ratio for minimum deflection is coming under "Smaller is-better" characteristic, which can be calculated as logarithmic transformation of the loss function [4]. Taguchi design the experiments using especially constructed tables known as "orthogonal arrays" (OA). The use of these tables makes the design of experiments very easy and consistent. The results of the sensitivity analysis for section A is as shown in Fig. 4.

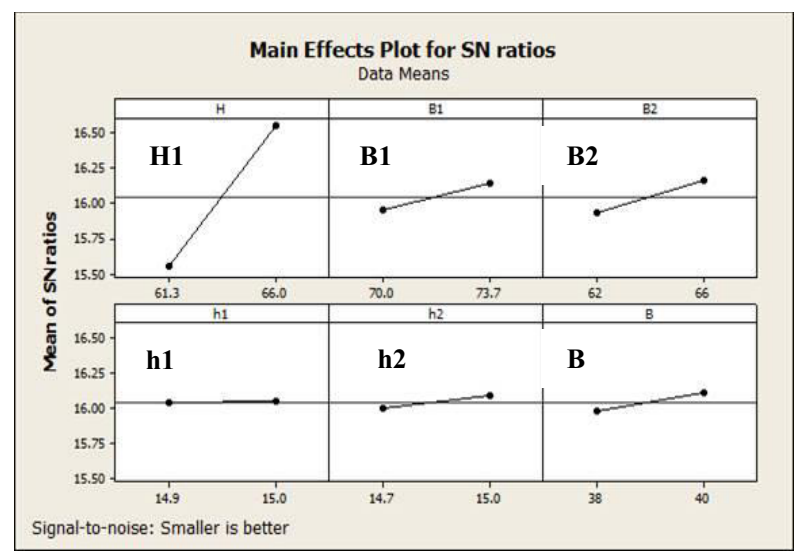

Figure 4. Sensitivity analysis for Start section A

Looking into the results of start section A, It is found that the level 2 of parameter web height $(\mathrm{H} 1)$ is good choice in sensitivity and plays value addition role in minimizing deflection. Increasing the web height (H1) as shown in Fig. 5 is beneficial to reduce the deflection of the section.

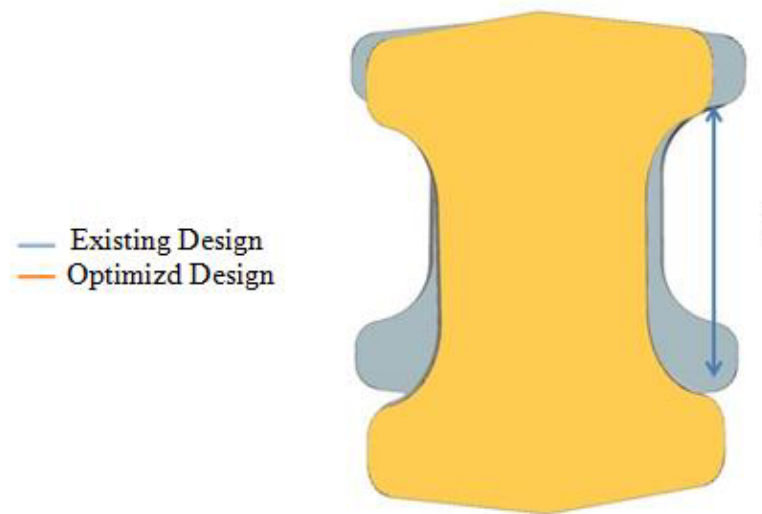

H1

Figure 5. Existing and optimized section A comparison and influencing parameter for deflection.

The results of the sensitivity analysis for middle section B is as shown in Fig. 6. Looking into the results of middle section $B$, It is found that the level 2 of 
parameters pad height (H2), web thickness (b) and lower flange height (e) are good choice in sensitivity and plays value addition role in minimizing deflection. Increasing the pad height (H2) and reducing web thickness (b) as well as lower flange height (e) as shown in Fig. 7 is beneficial to reduce the deflection of the section with optimum weight.

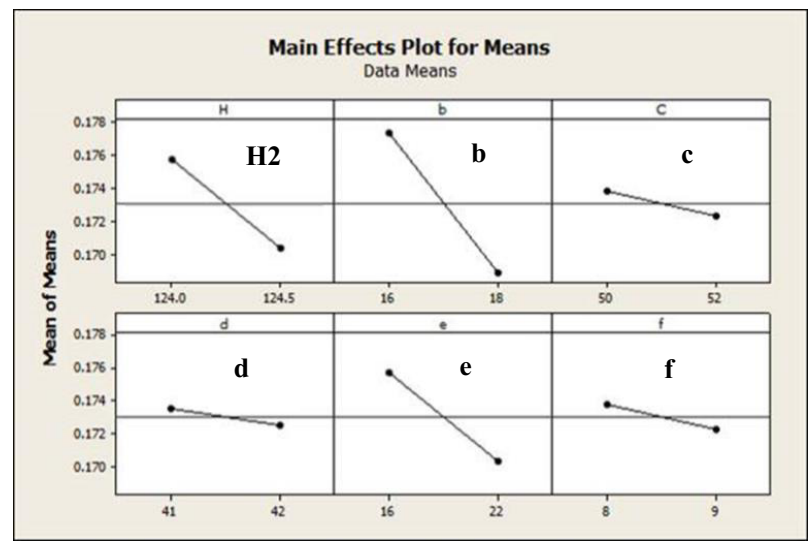

Figure 6. Sensitivity analysis for middle section B

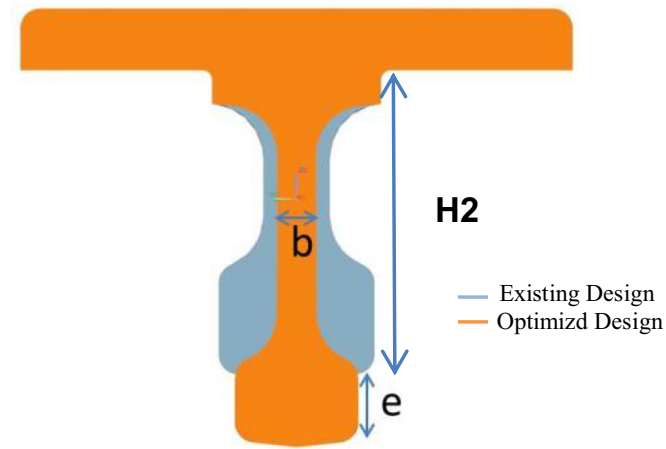

Figure 7. Existing and optimized section B comparison and influencing parameters for deflection.

The results of the sensitivity analysis for end section $\mathrm{C}$ is as shown in Fig. 8. Looking into the results of end section $\mathrm{C}$, It is found that the level 2 of parameters flange height (H3) and flange thickness (h1) are good choice in sensitivity and plays value addition role in minimizing deflection.

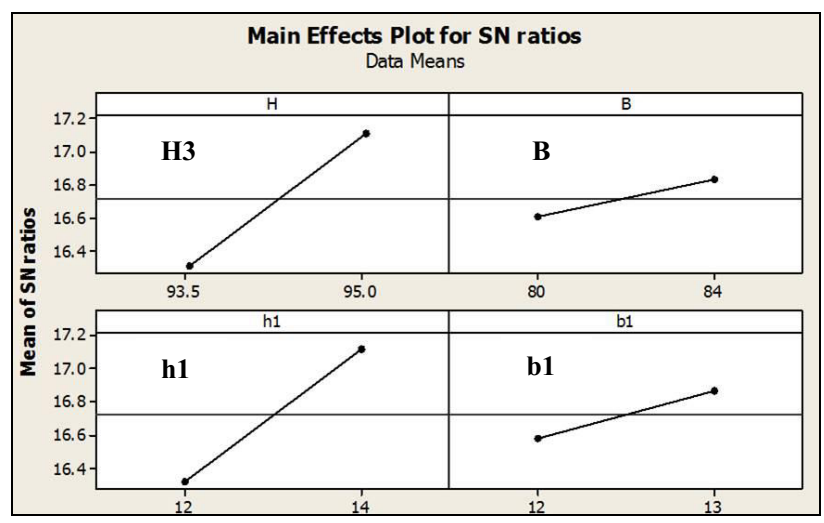

Figure 8. Sensitivity analysis for end section C

Increasing the flange height $(\mathrm{H} 3)$ and reducing the flange thickness (h1) as shown in Fig. 9 is beneficial to reduce the deflection of the section with optimum weight.

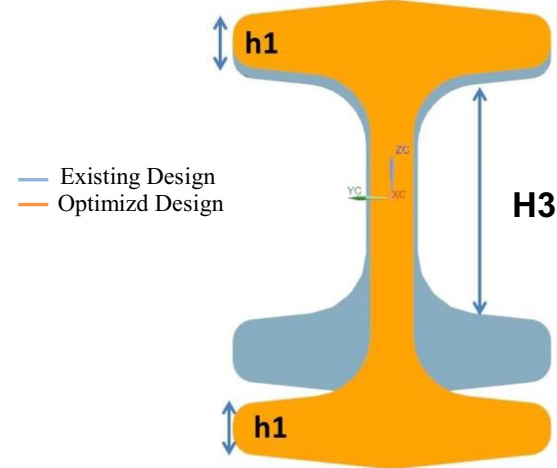

Figure 9. Existing and optimized section $\mathrm{C}$ comparison and influencing parameters for deflection.

It is also observed that, moment of inertia of each optimized sections is about 2 to $3 \%$ more than the existing section in all three directions [6]. In the investigation, it has been found that by optimizing the influencing parameters for respective sections will reduce the deflection as well as weight [7]. The stresses observed are consistent and in line with the existing design.

\section{Conclusions}

In this paper, the geometric parameter effect on deflection is studied using statistical Taguchi method. The $\mathrm{S} / \mathrm{N}$ ratios are analyzed with the deflection results by means of FE analysis. As a result, following conclusions are arrived at from this investigation.

1. The FEM-based Taguchi methods have effectively decreased the time and efforts required for evaluating and optimizing the design variables of chassis component.

2. The optimal parameter combination for the minimum weight with permissible value of deflection is obtained by using the analysis of $\mathrm{S} / \mathrm{N}$ ratio. According to the results slimmer section parameters are the optimal parameters for permissible deflection.

3. The most influencing parameter for section $\mathrm{A}$ is web height $(\mathrm{H} 1)$, by increasing this parameter deflection of this section under cantilever loading condition deceases to appreciable extent.

4. The most influencing parameter for section B is pad height (H2), web thickness (b) and lower flange height (e), by increasing pad height (H2) and decreasing web thickness (b) and lower flange height (e) the deflection of this section under cantilever loading condition decreases to appreciable extent.

5. The most influencing parameter for section $\mathrm{C}$ is web height (H3), flange thickness (h1) by increasing web height (H3) and reducing flange thickness (h1) the deflection of this section under cantilever loading condition deceases to appreciable extent.

6. The deflection performances of chassis components are greatly related to geometry of the structure, so by optimization of these sections substantially reduces the weight of the components.

\section{Acknowledgement}


The authors gratefully acknowledge the extended support provided to this work by KCTI (Kalyani Centre for Technology and Innovation) for providing financial funding, laboratory and library facilities. The authors also acknowledge the support provided by Bharat Forge Ltd, Pune and DSIR (Department of Scientific and Industrial Research), Govt. of India. Finally, the authors would like to express special thanks and gratitude to review committee and top management of Bharat Forge Ltd for granting the permission to publish/present the research work. Thanks to our departmental colleagues and others who helped us directly or indirectly.

\section{References}

1. IHS Automotive, sectorial report on "Weight Reduction in Automotive”, pp. 30-56, (2014).

2. Patel, H., Panchal, K. C., Jadav, C. S. Structural Analysis of Truck Chassis Frame and Design, International Journal of Engineering and Advanced Technology (IJEAT), 2;4, p. 665-668, (2013).
3. A. Yasar, D.A. Bircan, Design, Analysis and Optimization of Heavy Vehicle Chassis Using Finite Element Analysis, International Journal of Scientific and Technological Research, ISSN 2422-8702, Vol 1, No.6, (2015).

4. R.K Roy Design of Experiments Using The Taguchi Approach, Willy publication, ISBN-0-471-36101-1, pp. 95-171, (2001).

5. Wen-Hsien Hsua, Ching-Kong Chaoa, Hsi-Ching Hsub, Jinn Lin b, Ching-Chi Hsua, Parametric study on the interface pullout strength of the vertebral body replacement cage using FEM-based Taguchi methods, Medical Engineering \& Physics 31, 287294, (2009).

6. S. Tiwari, S. Kumar, V.Pattabiraman "A statistical approach towards connecting rod optimization" , SAE paper 2006-32-0068, Japan, (2006).

7. M. Ramgir, S. Neelkanth, I. Poonawala, "Design Optimization of Four Wheel Drive Tractor Front Axle Housing", International Journal of Engineering Research \& Technology (IJERT), ISSN: 2278-0181, Vol. 4 Issue 08, August-(2015). 